Revista Multidisciplinar do Nordeste Mineiro, v.2 2019/02

ISSN 2178-6925

\title{
OS TRANSEXUAIS E A ALTERAÇÃO DO PRENOME E DO SEXO NOS REGISTROS CIVÍS PÚBLICOS FACE A DECISÃO DA ADI 4275 DO SUPREMO TRIBUNAL FEDERAL
}

\section{TRANSEXUALS AND CHANGE OF NAME AND SEX IN PUBLIC CIVIL RECORDS FACTS DECISION OF ADI 4275 OF THE SUPREME FEDERAL COURT}

\section{Sâmara Camisão Pechir}

Pós Graduada em Direito Penal e Direito Processual Penal pelo Instituto Damásio de Direito. Atua como advogada há 03 anos nas áreas de Direito Civil, Direito Penal, Direito Trabalhista

e Previdenciário.

\section{Luana Pacheco Guimarães}

Pós Graduada em Direito Público pela Universidade Anhanguera de São Paulo nas áreas de Direito Constitucional, Administrativo, Tributário e Previdenciário, atua como advogada há 07 anos nas áreas de direito civil , administrativo e previdenciário, exerce atividade de Magistério junto a Faculdade Presidente Antônio Carlos de Teófilo Otoni/MG.

\begin{abstract}
Resumo
O presente artigo possui como principal objetivo abordar a forma de alteração dos registros públicos dos indivíduos transexuais ou transgêneros sob a ótica constitucional e sob o prisma da atual decisão proferida pela Suprema Corte brasileira, por intermédio da ADI 4275/2018. Trata-se de uma pesquisa documental e bibliográfica que se utilizou da legislação brasileira, como a Lei 6.015/73, a lei de Registros Públicos, do entendimento jurisprudencial, bem como da Constituição Federal de 1988, além disso, utilizou-se do entendimento doutrinário de autores como AMORIM (2011), ROCHA (2005), SCOTT (1995), VAMPRÉ (1935), VENOSA (2005) MALUF (2003) e VIEIRA (2008). O presente tema é de suma importância por se tratar de direitos fundamentais dos indivíduos transexuais, que não possuem expressa proteção legal, o que traz prejuízos e mitigam os direitos a dignidade, liberdade, igualdade, honra e imagem dessas pessoas. Deste modo, o estudo da temática em questão visa proporcionar mecanismos que assegurem a garantia dos direitos básicos e fundamentais aos transexuais.
\end{abstract}

Palavras-chave: Transexual. Transgênero, Registro Civil. Alteração doPrenome e Sexo.

\begin{abstract}
This article has as its main objective to address the way the alteration of the public records of transgender or transgender individuals from the constitutional point of view and from the perspective of the current decision of the Brazilian Supreme Court, through ADI 4275/2018. It
\end{abstract}


is a documentary and bibliographical research that used the Brazilian legislation, such as Law 6.015 / 73, the Law of Public Records, the jurisprudential understanding, as well as the Federal Constitution of 1988, in addition, it used the doctrinal understanding. by authors such as AMORIM (2011), ROCHA (2005), SCOTT (1995), VAMPRÉ (1935), VENOSA (2005) MALUF (2003) and VIEIRA (2008). The present theme is extremely important because it deals with the fundamental rights of transgender individuals, who do not have express legal protection, which damages and mitigates the rights to the dignity, freedom, equality, honor and image of these people. Thus, the study of the theme in question aims to provide mechanisms that ensure the guarantee of basic and fundamental rights to transsexuals.

Keyword: Transsexual. Transgender, Civil Registration. Change of First Name and Sex.

\section{Introdução}

Esse artigo tem como objetivo geral analisar a legislação pátria existente acerca do tema os transexuais e a alteração do prenome e do sexo nos registros civis públicos face à decisão da ADI 4275 do Supremo Tribunal Federal, através da consulta a legislação existente, estudou-se as dificuldades que os indivíduos transexuais ou transgêneros enfrentam de alterar o prenome e o sexo perante os registros públicos. O enfoque deste artigo mostra-se extremamente importante em face da realidade atual, em que os transexuais buscam alterar o seu nome e encontram diversos obstáculos.

Os questionamentos que deram direcionamento aoestudo foram:

- A legislação brasileira permite que os transexuais ou transgêneros alterem seus registros públicos no tocante aos prenomes e à sexualidade?

- Existe um entendimento pacificado na jurisprudência acerca da alteração dos prenomes e do sexo dos transgêneros no ordenamento jurídico brasileiro?

- A legislação brasileira, no tocante a permissão ou não da alteração dos registros públicos, atende aos princípios constitucionais da dignidade, igualdade e liberdade dos indivíduos transexuais e trangêneros?

Para se alcançar os objetivos almejados no presente estudo, utilizou-se da análise da legislação, da jurisprudência e de doutrinas jurídicas, fundamentando-se em teses e entendimentos de autores como: Joan Scott (1995), Rocha (2007) e Amorim (2011) que realizam uma conceituação e definição do que é gênero e sexo pode se confundir com o sexo, fazendo também uma análise acerca da identificação sexual dos indivíduos. Vieira (2008) também realiza uma definição do transexual, enquanto Vampre (1935) e Venosa (2005) demonstram a importância do nome para 
o indivíduo. Por fim, Maluf (2003) demonstra as fundamentações utilizadas nas decisões que concedem aos transexuais o direito à alteração de seus prenomes.

\section{Desenvolvimento}

Inicialmente, mostra-se necessário para facilitar o entendimento e fornecer maior fluidez ao presente estudo, antes de se adentrar na definição do que é a transexualidade, realizar uma conceituação acerca do gênero e da identidade.

Deste modo, conforme os ensinamentos de Joan Scott (1995, p. 71-72), o gênero pode ser definido como um componente essencial para definir 0 comportamento atribuído às mulheres e aos homens dentro de uma sociedade, ou seja, o papel que cada um deles exerce dentro das relações com base nas diferenças existentes entre os sexos, mas que não pode se confundir com o sexo.

Neste sentido, Rocha (2007, p.644) entende que sexo é apenas o grupo de caracteres funcionais, que compõe a estrutura e que definem o ser vivo como macho ou fêmea. Assim, esses caracteres biológicos, tais como as genitais ou os órgãos reprodutores, bem como os órgãos que produzem os hormônios inerentes a cada sexo, definem o sexo.

A doutrinadora Linamar Teixeira de Amorim (2011) realiza então uma diferenciação do gênero e do sexo, entendendo que o gênero tem a função de determinar tudo aquilo que pode ser entendido como social e cultural, tendo um caráter mutável, pois conceitua-se constantemente de acordo as interações dos indivíduos dentro de um contexto social, e jamais pode ser definindo como um sinônimo do sexo, face a toda discussão histórica que existe acerca desta definição.

Feitas tais considerações, percebe-se que o gênero pode ser entendido como a identificação que um ser humano possui face as suas genitais e a função que o indivíduo possui na sociedade, enquanto o sexo é a definição que decorre da estruturação física do indivíduo.

Rocha (2007) vai além em suas análises e por meio de suas reflexões constata que os indivíduos possuem a vontade de se encaixar em um dos gêneros, o que resulta no surgimento de um direito individual de identificação sexual.

Neste sentido, Rocha (2007) define a Identidade sexual como aquilo que faz parte da identidade pessoal de cada indivíduo e que possui tanta relevância quanto os demais direitos fundamentais aos cidadãos. Assim, o direito à identidade sexual é 
entendido como a forma como a pessoa deseja ser entendida e compreendida perante a sociedade em que ela faz parte, podendo ser entendido inclusive, como um dos direitos de personalidade.

A figura do transexual ou transgênero pode, inicialmente, ser entendido como os indivíduos de qualquer sexo, que possuam uma identidade de gênero que diverge da sua condição biológica, ou seja, suas genitais, conforme expõe-se a seguir.

A Resolução nำ1.955/2010 do Conselho Federal de Medicina - CFM (2010), em seu art. $3^{\circ}$ define o transexualidade como:

Art. 3ำ Que a definição de transexualismo obedecerá, no mínimo, aos critérios abaixo enumerados:

1) Desconforto com o sexo anatômico natural;

2) Desejo expresso de eliminar os genitais, perder as características primárias e secundárias do próprio sexo e ganhar as do sexo oposto;

3) Permanência desses distúrbios de forma contínua e consistente por, no mínimo, dois anos;

4) Ausência de outros transtornos mentais. (Onde se lê "Ausência de outros transtornos mentais", leia-se "Ausência de transtornos mentais")

Da mesma maneira, Tereza Rodrigues Vieira (2008, p. 221) que o transexual pode ser definido como aquele que possui uma neurodiscordância de gênero, ou seja, o transgeneralismo, onde o indivíduo não aceita sua condição biológica e age como se possuísse o sexo oposto, chegando a buscar, inclusive, intervenções médicas, como tratamentos hormonais ou cirúrgicas e em casos graves, até mutilações para como forma de se evitar os seus conflitos internos e externos.

Portanto, a transexualidade pode ser vista como um distúrbio de gênero que existe o indivíduo possui determinado sexo biológico, mas sua identidade sexual e de gênero não correspondem.

Importante consignar que o conceito de transexual está inserido dentro do conceito de transgênero, vez que este último se trata de pessoa que nasceu com determinado sexo biológico, e não se identifica com o seu corpo. Um exemplo é o sujeito que nasceu com genitália masculina, cresceu com as transformações causadas pelos hormônios masculinos, mas sua identificação é com o físico feminino.

Situado no campo conceitual do transgênero está o transexual, aquele(a)que além de se identificar com o sexo oposto, empenha esforços para tornar sua aparência similar a este, essas pessoas se submetem a tratamentos hormonais para 
alterar a aparência, modificam a voz e, com autorização psiquiátrica, realizam cirurgias de redesignação sexual e outras intervenções cirúrgicas que forem necessárias.

A Declaração Universal do Genoma Humano e dos Direitos Humanos (1997) prevê em seu art. $2^{\circ}$ que todos os indivíduos possuem direito à dignidade e aos direitos humanos, independentemente de suas características genéticas, não podendo se diminuir ou distratar os indivíduos em decorrência de suas características genéticas, devendo-se respeitar, acima de tudo, as individualidades e diversidades de todos os seres humanos.

Deste modo, fica evidenciado que os direitos à personalidade inerentes a pessoa humana devem ser respeitados independente da condição sexual ou de gênero ao qual o indivíduo esteja submetido, afinal, o Código Civil (Brasil, 2002), determina, em seu art. $2^{\circ}$, que a personalidade da pessoa civil começa a partir do nascimento com vida, devendo-se ressaltar que o referido artigo não faz menção alguma a qualquer condição física, biológica ou psíquica do indivíduo, bastando apenas que esse nasça para que seja titular de direitos.

Dentre os direitos da personalidade, busca-se destacar no presente trabalho, o direito ao nome, que pode ser facilmente percebido como um dos principais direitos que o indivíduo possui, conforme ensina Spencer Vampre (1935, p. 38) ao inferir que o nome é a forma mais comum e mais prática de se realizar a identificação do cidadão.

O direito ao nome possui relevância no âmbito internacional, haja vista o fato de que legislações internacionais, como a Convenção Americana dos Direito Humanos preveem tal direito, conforme demonstra-se:

Art. 18 da Convenção Americana dos Direitos Humanos. Direito ao nome: Toda pessoa tem direito a um prenome e aos nomes de seus pais ou ao de um destes. A lei deve regular a forma de assegurar a todos esse direito, mediante nomes fictícios, se for necessário.

Seguindo a mesma linha de raciocínio, a legislação brasileira confere bastante atenção e proteção ao direito ao nome, como pode se demonstrar por intermédio do Código Civil (Brasil, 2002), que o classifica como um direito a personalidade:

Art. 16 do Código Civil de 2002. Toda pessoa tem direito ao nome, nele compreendidos o prenome e o sobrenome. 
Da mesma maneira, a Lei 6.015 de 1973, a Lei de Registros Públicos determina que o nome deve constar obrigatoriamente no assento do nascimento de todo indivíduo, conforme demonstra-se:

Art. 54 da Lei 6.015 de 1973. O assento do nascimento deverá conter: (Renumerado do art. 55, pela Lei oㅜ 6.216, de 1975).

$\left.4^{\circ}\right)$ o nome e o prenome, que forem postos à criança; (Brasil, 1973)

Além disso, o Código Civil (Brasil, 2002) buscou proteger o direito ao nome, conforme pode ser analisado através do disposto no art. 17, onde está determinado que o nome da pessoa não pode ser empregado por outro indivíduo em qualquer publicação ou representação que exponha o indivíduo ao desprezo público, mesmo que não exista o dolo de difamá-lo. Além disso, o art. 18 da referida lei também proíbe o uso não autorizado do nome de alguém em qualquer propaganda comercial.

O nome possui extremada importância para todos os indivíduos de uma sociedade, tratando-se inclusive de um direito à personalidade, funcionando como um mecanismo que torna cada cidadão único, e conforme entendimento de Silvio de Salvo Venosa (2005, p. 211) é sem sombra de dúvidas, a manifestação que mais expressa a personalidade.

O nome é uma forma de individualização do ser humano na sociedade, mesmo após a morte. Sua utilidade é tão notória que há a exigência para que sejam atribuídos nomes a firmas, navios, aeronaves, ruas, praças, acidentes geográficos, cidades etc. $O$ nome, afinal, é o substantivo que distingue as coisas que nos cercam, e o nome da pessoa a distingue das demais, juntamente com outros atributos da personalidade dentro da sociedade. É pelo nome que a pessoa fica conhecida no seio da família e da comunidade em que vive. (Venosa 2005, p. 211)

Venosa ainda demonstra alguns outros pontos importantes acerca do instituto do nome, como o fato de que o direito ao Nome fornece mecanismos ao Estado que contribuem para segurança da população:

Pelo lado do direito público, o Estado encontra no nome fator de estabilidade e segurança para identificar as pessoas; pelo lado dodireito privado, o nome é essencial para o exercício regular dos direitos e do cumprimento das obrigações. Venosa (2005, p. 212) 
Como demonstrado, o nome é um instituto de interesse público e privado ao mesmo tempo, tendo proteção jurídica até mesmo no âmbito internacional. Desta maneira, alterar um nome, segundo a antiga redação do art. 58 da Lei de Registros Públicos, lei 6.015 de 1973 era uma tarefa árdua face ao princípio que regia o referido artigo, conforme demonstra-se a seguir:

Art. 58 da Lei 6.015/73. O prenome será imutável. (Renumerado do art. 59, pela Lei $n^{\circ}$ 6.216, de 1975) (Revogado). (Brasil, 1973)

No entanto, a lei o 9.708 de 1998 alterou o art. 58 da Lei no 6.015/73, trazendo agora a possibilidade de se alterar os prenomes por apelidos públicos notórios, conforme demonstra-se a partir da nova redação do art. 58:

Art. 58 da Lei 6015/73. O prenome será definitivo, admitindo-se, todavia, a sua substituição por apelidos públicos notórios. (Brasil, 1973)

Assim, como verificado, a imutabilidade do Nome Civil é um dos princípios que norteiam e regulam o direito ao nome, configurando-se como um princípio de natureza pública que visa a garantia da segurança das relações de direitos e obrigações dentro da sociedade, evitando-se que um indivíduo altere a todo momento seu nome para fraudar ou causar danos a outrem.

Ao se analisar o parágrafo único do art. 55 da Lei 6.015/73, verifica-se outra proteção concedida pela legislação, onde os oficiais do registro civil podem recusar os prenomes que exponham os indivíduos a uma situação vexatória, ou nas palavras da lei, "prenomes que possam expor as pessoas ao ridículo", conforme demonstra-se:

Parágrafo único do Art. 55 da Lei no $\mathbf{6 . 0 1 5 / 7 3}$. Os oficiais do registro civil não registrarão prenomes suscetíveis de expor ao ridículo os seus portadores. Quando os pais não se conformarem com a recusa do oficial, este submeterá por escrito o caso, independente da cobrança de quaisquer emolumentos, à decisão do Juiz competente. (Brasil, 1973)

Observa-se que nos casos em que os pais do indivíduo não concordarem com a decisão do oficial de registro, este poderá levar o caso ao conhecimento do juiz que irá proferir uma decisão judicial.

No entanto, mesmo com as proteções legais demonstradas acima, ainda existem cidadãos que por descuido ou inobservância foram nominados de forma 
vexatória, o que lhes traz desconforto e constrangimentos ao longo de suas vidas. Nesse caso, a lei de Registros Civis determina em seu art. 56 a seguinte possibilidade:

Art. 56 da Lei 6.015/73. O interessado, no primeiro ano após ter atingido a maioridade civil, poderá, pessoalmente ou por procurador bastante, alterar o nome, desde que não prejudique os apelidos de família, averbando-se a alteração que será publicada pela imprensa. (Brasil, 1973)

Deste modo, a lei permite que o cidadão altere seu prenome, ressalvado seus sobrenomes, até o fim do primeiro ano depois de ter atingido a maioridade civil, ou seja, aos 18 anos.

Além das previsões legais mencionadas, existem outros mandamentos legislativos previstos na Lei de Registros civis que, a título exemplificativo, permitem a alteração do prenome de vítimas e testemunhas ameaçadas ou dos cônjuges, companheiros e descendentes ou ascendentes desses indivíduos, desde que ouvido o ministério público.

Existe ainda as alterações do prenome que podem ser realizadas por causa da existência de algum erro na grafia do nome ou outros erros que não necessitam de indagação para a correção, conforme art. 110 da Lei 6.015/73, que teve sua redação alterada pela lei no 13.484 de 2017, passando a vigorar da seguinte maneira:

\footnotetext{
Art. 110 da Lei $6.015 / 73$. O oficial retificará o registro, a averbação ou a anotação, de ofício ou a requerimento do interessado, mediante petição assinada pelo interessado, representante legal ou procurador, independentemente de prévia autorização judicial ou manifestação do Ministério Público, nos casos de: (Redação dada pela Lei № 13.484, de 2017)

I - erros que não exijam qualquer indagação para a constatação imediata de necessidade de sua correção; (Incluído pela Lei no 13.484, de 2017) (Brasil, 1973)
}

Contudo, existe ainda a figura dos transexuais ou transgêneros que só tomam conhecimento de sua condição biopsicólógica anos ou décadas depois de seu nascimento, momento em que já tem seu prenome definido, o que muitas vezes ocorre após a maioridade do indivíduo, o que impossibilita a alteração, ou ainda, são impedidos pelo medo da repulsa da sociedade aos quais são submetidos.

É salutar mencionar que a transexualidade não enseja o direito à troca do prenome no ordenamento jurídico brasileiro, haja vista a ausência de legislação para 
o caso específico, o que faz com que cada magistrado analise o caso com base em outras fontes do direito que não a lei.

Nesse sentido, conforme a doutrinadora Adriana Maluf (2003, p.66), as decisões judiciais que concediam a tutela para alteração dos prenomes dos transexuais são fundadas nos princípios da dignidade da pessoa humana, ou no direito a identidade e liberdade do indivíduo, conforme demonstra-se:

[...] afirmam atender ao princípio da isonomia, previsto nos artigos 1으. III, IV e $3^{\circ}$, III, IV da CF, que proíbe qualquer prática discriminatória para a dignidade da pessoa humana, para os valores sociais do trabalho e da livre iniciativa, acesso ou manutenção do trabalho por motivo de sexo, origem, raça, cor, estado civil, situação familiar ou idade. (Maluf, 2003, p.66).

Deste modo, face a ausência legislativa e a complicada odisseia ao qual os transexuais são submetidos para conquistar o direito a alterar seu próprio nome, muitos deles optam por outras soluções, que por muitas vezes, trazem uma série de transtornos e constrangimentos para a vida em sociedade.

Um desses mecanismos utilizados é a utilização de um Nome Social, que pode ser entendido como um nome ao qual os indivíduos transexuais e transgêneros se utilizam na vida em sociedade em detrimento do nome que fora registrado em cartório que diverge de sua identidade de gênero.

O estado do Rio Grande do Sul, por intermédio do decreto no 48.118/2011, com base nos princípios da dignidade da pessoa humana, na igualdade e na liberdade individual criou uma legislação que dispõe acerca do tratamento nominal e da inclusão do nome social de transexuais e travestis nos registros estaduais que tem correlação com a prestação de serviços públicos no campo estadual, trazendo, em seu art. $1^{\circ}$, o seguinte mandamento:

\begin{abstract}
Art. 1ㅇ do Decreto no 48.118 de 2011. Nos procedimentos e atos dos Órgãos da Administração Pública Estadual Direta e Indireta de atendimento a travestis e transexuais deverá ser assegurado o direito à escolha de seu nome social, independentemente de registro civil, nos termos deste Decreto. Parágrafo único. Para fins deste Decreto, nome social é aquele pelo qual travestis e transexuais se identificam e são identificados pela sociedade. (Rio Grande do Sul, 2011)
\end{abstract}

Entretanto, mesmo com os avanços da legislação trazida pelo estado do Rio Grande do Sul, tal entendimento sempre foi tratado com divergência por outros 
estados, nunca tendo existido um consenso quando a matéria de fato, conforme se demonstra através do julgado do Tribunal de Justiça do Estado de São Paulo.

RETIFICAÇÃO DE REGISTRO CIVIL - Pedido de alteração de nome e sexo - Possibilidade apenas em relação ao nome - Pessoa que apesar de não submetida à cirurgia de transgenitalização, se apresenta na sociedade como do sexo feminino - Nome masculino que the acarreta constrangimentos e aborrecimentos - Admitida a alteração do nome, negada a alteração para constar ser do sexo oposto - Observância do princípio de veracidade do registro público - Recurso parcialmenteprovido.

TJSP. APL: 320109120108260602.Relator: Mendes Pereira. Data de Julgamento: 28/11/2012, $7^{\text {a }}$ Câmara de Direito Privado, Data de Publicação: 05/12/2012. (São Paulo, 2012).

Observa-se que, mesmo entendendo que a mudança do nome do indivíduo é possível face à sua identificação perante a sociedade, o Tribunal de Justiça de São Paulo não admitiu a retificação do sexo no registro civil, pois tal retificação não coaduna com a veracidade do que fora registrado no registro público, ou seja, pelo fato do transexual não possuir o sexo que se identifica, ele não poderia ter retificado sua sexualidade.

Ocorre que o Supremo Tribunal Federal, por intermédio da ADI 4275, entendeu que a alteração do nome e do gênero de um indivíduo no assento de registro civil pode ser perfeitamente realizado sem a realização de qualquer procedimento cirúrgico de redesignação de sexo, conforme demonstra-se:

\begin{abstract}
Decisão: O Tribunal, por maioria, vencidos, em parte, os Ministros Marco Aurélio e, em menor extensão, os Ministros Alexandre de Moraes, Ricardo Lewandowski e Gilmar Mendes, julgou procedente a ação para dar interpretação conforme a Constituição e o Pacto de São José da Costa Rica ao art. 58 da Lei $6.015 / 73$, de modo a reconhecer aos transgêneros que assim 0 desejarem, independentemente da cirurgia de transgenitalização, ou da realização de tratamentos hormonais ou patologizantes, 0 direito à substituição de prenome e sexo diretamente no registro civil. Impedido o Ministro Dias Toffoli. Redator para o acórdão o Ministro Edson Fachin. Presidiu o julgamento a Ministra Cármen Lúcia. Plenário, 1ํ.3.2018. (grifo nosso) (Brasil, 2018)
\end{abstract}

Deste modo, o STF pacificou e determinou um novo entendimento acerca da retificação do nome e do sexo dos transexuais, passando a entender que a partir de agora o artigo 58 da Lei 6.015/1973, que trata sobre os registros públicos, permite a alteração de prenome e gênero no registro civil mediante averbação no registro original, sendo dispensável a realização da cirurgia de troca de sexo do indivíduo. 
Neste sentido, segue o voto do relator, o Ministro Marco Aurélio:

Julgo parcialmente procedente o pedido para assentar, como interpretação do artigo 58 da Lei no 6.015/1973 compatível com a Constituição Federal, a possibilidade de mudança de prenome e gênero no registro civil, mediante averbação no registro original, condicionando- se a modificação, no caso de cidadão não submetido à cirurgia de transgenitalização, aos seguintes requisitos: (i) idade mínima de 21 anos; e (ii) diagnóstico médico de transexualismo, presentes os critérios do artigo $3^{\circ}$ da Resolução $n^{\circ}$ 1.955/2010, do Conselho Federal de Medicina, por equipe multidisciplinar constituída por médico psiquiatra, cirurgião, endocrinologista, psicólogo e assistente social, após, no mínimo, dois anos de acompanhamento conjunto. Tenho como inconstitucional interpretação do artigo que encerre a necessidade de cirurgia para ter-se a alteração do registro quer em relação ao nome, quer no tocante aosexo. (Brasil, 2018)

Assim, ficou determinado que, com base nos princípios da não discriminação por razão de orientação sexual ou identificação de gênero, nos princípios da igualdade e da liberdade individual, e também nos direitos à imagem, à vida privada, conforme voto da Ministra Carmen Lúcia, a ADI foi julgada procedente, concedendo uma interpretação constitucional ao art. 58 da lei dos registros públicos, reconhecendo aos transgêneros 0 direito à alteração de nome e gênero nos assentos de registro civil.

A doutrinadora Tereza Vieira $(2008$, p.331) entende que o meio mais sensato para solucionar esse empasse jurídico, que assola os transexuais, seria a criação de leis que permitiam a alteração dos prenomes de maneira específica, o que evitaria decisões arbitrárias por parte dos magistrados e evitaria a divergência jurisprudencial.

\section{Considerações finais}

Conforme demonstrado no presente trabalho, o direito ao nome é um dos principais direitos de um cidadão, principalmente por se tratar de um direito de personalidade, que dá significado e identificação ao indivíduo tanto perante a sociedade, quanto perante a si mesmo. Do mesmo modo, a identidade de gênero do indivíduo possui a mesma relevância, haja vista que é por ela que o cidadão se define perante à sociedade.

A ausência legislativa no ordenamento jurídico brasileiro que permitia a alteração do prenome dos transexuais abria margem para entendimentos jurisprudenciais que divergiam entre si, onde parte primava pela proteção dos 
terceiros que poderiam ser afetados por uma alteração eivada de má fé, e em contrapartida, a outra parte se pautava nos direitos a dignidade da pessoa humana, da liberdade e da igualdade.

É fato que apenas a criação de legislações não seriam o suficiente para extinguir toda a problemática, contudo, seria de fato um passo fundamental que garantiria o direitoa diversidade sexual e a dignidade dos transexuais, contribuindo diretamente para o exercício da cidadania desses indivíduos.

A decisão do Supremo Tribunal Federal, por meio da ADI 4275, conferiu aos transexuais o direito a igualdade, o que contribuirá para se evitar a discriminação e 0 preconceito, garantindo também o direito à honra, à imagem, à liberdade e principalmente a dignidade desses indivíduos.

Deste modo, conclui-se que a legislação deve seguir o entendimento da suprema corte brasileira, o que contribuirá diretamente para a construção de uma sociedade justa e igualitária. Para tanto, o Congresso Nacional deve criar e aprovar legislações que reiterem o novo entendimento do Supremo Tribunal Federal, concedendo aos transexuais, de maneira ainda mais efetiva, o direito a dignidade da pessoa humana, bem como sua inserção numa sociedade mais justa e menos preconceituosa.

\section{Referências}

AMORIM, Linamar Teixeira de. Gênero: uma construção do movimento feminista? In: Anais II Simpósio Gênero e Políticas Públicas. Londrina - SP. 2011. Disponível em: <http://www.uel.br/eventos/gpp/pages/arquivos/Linamar.pdf>. Acesso em: $10 \mathrm{de}$ abril de 2018.

BRASIL. Conselho Federal de Medicina. Resolução no 1.955 de 12 de agosto de 2010. Dispõe sobre a cirurgia de transgenitalismo e revoga a resolução CFM no 11.652/02. Brasília-DF. Disponível em: <http://www.portalmedico.org.br/resolucoes/CFM/2010/1955_2010.htm>. Acesso em 10 de abril de 2018

BRASIL. Constituição da República Federativa do Brasil de 1988. Casa Civil, Subchefia de Assuntos Jurídicos: Disponível em: <http://www.planalto.gov.br/ccivil_03/constituicao/constituicaocompilado.htm>. Acesso em 12 de fevereiro de $20 \overline{1} 8$

BRASIL. Lei no 6.015, de 31 de dezembro de 1973. Lei de Registros Públicos. Planalto. Disponível em:<http://www.planalto.gov.br/ccivil_03/leis//6015consolidado.htm>. Acesso em: 08 de abril de 2018 
BRASIL. Lei no 9.708, de 18 de novembro de 1998. Altera o art. 58 da Lei no 6.015, de 31 de dezembro de 1973, que dispõe sobre Registros Públicos, para possibilitar a substituição do prenome por apelidos públicos notórios. Disponível em:

<http://www.planalto.gov.br/ccivil_03/leis/L9708.htm\#art1>. Acesso em: 10 de abril de 2018

BRASIL. Lei no 10.406, de 10 de janeiro de 2002: Código Civil de 2002. Disponível em: <http://www.planalto.gov.br/ccivil_03/leis/2002//10406.htm>. Acesso em: 12 abril de 2018

BRASIL. Rio Grande do Sul. Assembléia Legislativa. Decreto no 48.118 de 27 de junho de 2011. Dispõe sobre o tratamento nominal, inclusão e uso do nome social de travestis e transexuais nos registros estaduais relativos a serviços públicos prestados no âmbito do Poder Executivo Estadual e dá providências. Disponível em: <http://www.al.rs.gov.br/filerepository/repLegis/arquivos/DEC\%2048.118.pdf>. Acesso em: 12 de abril de 2018.

BRASIL. Supremo Tribunal Federal. ADI/4275 - Ação Direta de Inconstitucionalidade. Relator: Min. Marco Aurélio. Publicado no DOU em: 09 de março de 2018. Disponível em:

<http://stf.jus.br/portal/diarioJustica/verDiarioProcesso.asp?numDj=45\&dataPublicac aoDj=09/03/2018\&incidente $=2691371 \&$ codCapitulo $=2 \&$ numMateria $=5 \&$ codMateria $=4$ >. Acesso em: 12 de abril de 2018

BRASIL. Tribunal de Justiça do Estado de São Paulo. APL:

320109120108260602. Relator: Mendes Pereira. Data de Julgamento: 28/11/2012, $7^{\text {a }}$ Câmara de Direito Privado, Data de Publicação: 05/12/2012. In: JusBrasil. Disponível em: <http://tjsp.jusbrasil.com.br/jurisprudencia/22785089/apelacao-apl-320109120108260602-sp0032010-9120108260602-tjsp>. Acesso em: 12 de abril de 2018.

COSTA RICA. Convenção Americana Sobre Direitos Humanos. Conferência Especializada Interamericana sobre Direitos Humanos, San José, Costa Rica, em 22 de novembro de 1969. Disponível em:

$<$ https://www.cidh.oas.org/basicos/portugues/c.convencao_americana.htm>. Acesso em: 12 de abril de 2018

MALUF, Ângela Cristina Munhoz. Brincar prazer e aprendizado. Petrópolis, RJ:Vozes,2003.

ROCHA, Ruth. Minidicionário da Língua Portuguesa, Ed. Scipione, 2005, São Paulo - SP

SCOTT, Joan. Gênero: uma categoria útil de análise histórica. In: Educação e Realidade. Porto Alegre, v. 20, n.2, jul./dez. 1995, pp. 71 -99.

UNESCO. Declaração Universal do Genoma Humano e dos Direitos Humanos. 1997. Disponível em: 
$<$ http://unesdoc.unesco.org/images/0012/001229/122990por.pdf1>. Acesso em: 08 de abril de 2018

VAMPRÉ, Spencer. Do nome civil. Rio de Janeiro: F. Briguiet\& Cia, 1935, p. 38.

VENOSA, Silvio de Salvo.Direito Civil, 5ำ edição, Ed. Atlas, 2005, São Paulo - SP

VIEIRA, Tereza Rodrigues - Nome e Sexo - mudanças no registro civil, Ed. Revista dos Tribunais, 2008, São Paulo - SP 